\title{
New Control Algorithms for Microgrids Based on Microturbines
}

\author{
I. Leibar, I. Zamora, P. Eguia, J.I. San Martin \\ Department of Electrical Engineering \\ University of Basque Country - UPV/EHU \\ Alda. Urquijo, s/n, 48013 Bilbao (Spain) \\ e-mail: inmaculada.zamora@ehu.eus
}

\begin{abstract}
This paper analyses the performance of a lowvoltage microgrid, based on microturbines, and presents new control algorithms to improve the efficiency and reliability of microgrids. Due to the importance of islanding and focusing on the efficiency and the harness of the heat of the exhaust gasses in islanded operation mode, a new control algorithm has been developed. Additionally, a new control strategy is presented for the seamless transition between islanded and grid connected operation modes based on changing the control algorithms of the microturbines.
\end{abstract}

The new proposed control algorithms are tested by simulation using a low voltage network fed by 5 microturbines. Lasseter model is used to represent the dynamic behaviour of the microturbines. The paper shows the simulation results and the main conclusions of the validation process.

\section{Key words}

Microturbine, microgrid, control algorithm, combined heat and power, islanding.

\section{Introduction}

In addition to providing a solution for supplying power to isolated areas, decentralized generation appears to be a good solution for reducing transmission and distribution losses. Besides, using combined heat and power in microgrids provides opportunities to improve energy efficiency and power reliability. Among the different options, microturbines are a very interesting solution for the decentralized generation due to their simplicity, low maintenance costs, ability to operate with all types of fuels and, above all, the development of equipment for the recovery of the thermal energy of the exhaust gases and its use for cogeneration and trigeneration.

To take advantage of the full potential of microgrids, and the generation systems installed in them, the microgrid must be able to transition automatically from being connected to the distribution network to operate isolated, without service interruption. The transition between standalone and grid connected modes, and the necessary voltage synchronization, have been studied in [1]-[2]. Moreover, automatic fault detection in the utility network for the necessary transition between connected and islanded mode has been studied in [3]. However, it is still necessary to develop control strategies applied to generation systems to automatically transition between both modes with reduced voltage and current transients.

In this context, when the microgrid operates in standalone mode, voltage and frequency must be controlled. There are two main approaches to this issue:

- Master slave control algorithms [4], in which voltage and frequency control is performed by one of the generators (master).

- "Droop" controls [5], in which each generator responds to the voltage and frequency variations proportionally according to its droop setting.

However, when microturbines are used, neither strategy considers the thermal energy needs of each user. So, in this paper, a centralized voltage and frequency control algorithm for islanded operation, that considers those needs is proposed.

The paper is organized as follows. Section 1 corresponds to this introduction. Section 2 describes the microturbine model and its controls for grid connected and islanded operation. Section 3 introduces the new centralized control algorithm for islanded operation mode. Section 4 describes the new control algorithm for transition between operation modes. Section 5 shows the simulation results for validating the proposed algorithms and Section 6 concludes the paper.

\section{Microturbine model}

The microturbine generation system has been modelled according to the model presented by Lasseter [6]. The generator and the rectifier have been modelled as a diode bridge powered by a permanent magnet alternator, assuming that losses are negligible. It is an integrated 


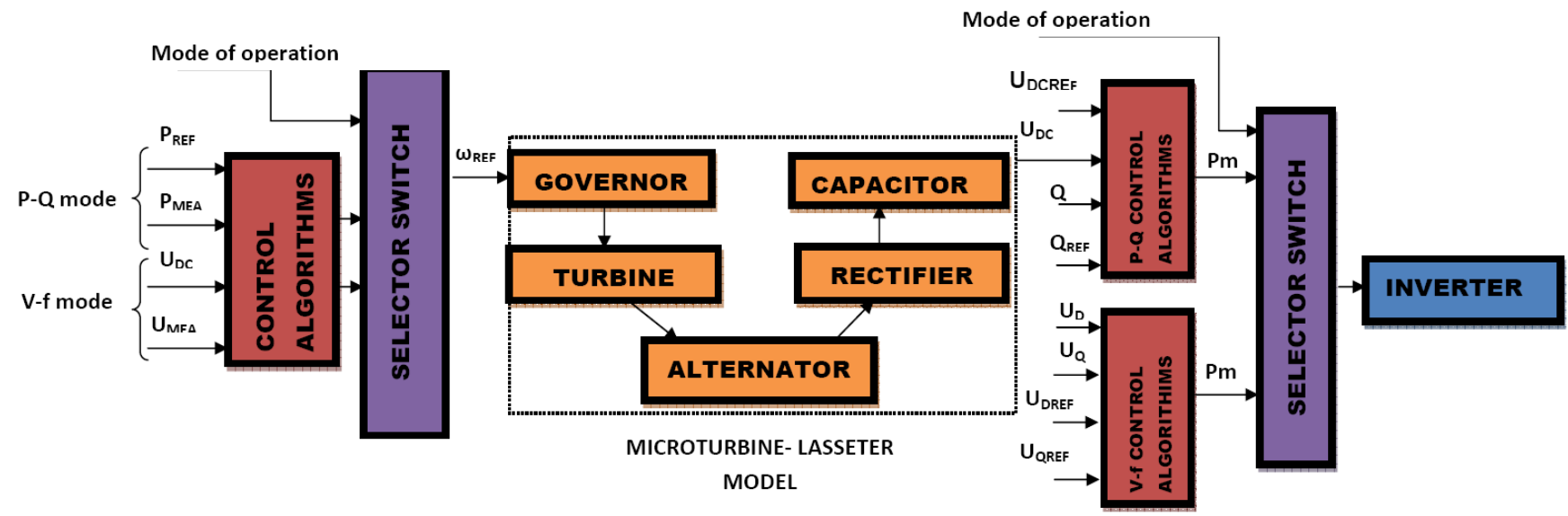

Fig 1. Microturbine generation system model structure

model of turbine, generator and rectifier, which is useful for most dynamic studies.

Lasseter model is based on Rowen gas turbine model [7], where some simplifications are assumed. Thus, the recuperator has not been modelled, because the aim is the analysis of the electrical system. Neither the acceleration control or the temperature control have been included. The acceleration control is used to protect the microturbine from the thermal stress generated at the system start-up, when the microturbine must reach the operating temperature [8]. For this reason, a maximum acceleration rate is set until the end of the start-up process. On the other hand, the main function of the temperature control is to limit the output power of the microturbine to a predetermined value, regardless of the variation of the ambient temperature or the characteristics of the fuel. As in the case of the acceleration control, the modelling of this control can be simplified, assuming that it operates within the operating limits of the machine [9]. Thereby, the model is valid for analysis focused on the electric performance, in which the start of the microturbine is not analysed and it works within the limits of operation.

Figure 1 shows the scheme of the model, the model elements, the integration of the control algorithms and the signals needed for these controls. The generation system has been connected to the network through a PWM (pulse width modulation) inverter and a coupling-impedance.

The calculation of the reference speed applied to the controller is performed using different control algorithms, depending on the mode of operation. In the case of grid connected operation, the reference speed of the microturbine is determined from the active power input $\left(\mathrm{P}_{\mathrm{REF}}\right)$ and the measured active power $\left(\mathrm{P}_{\mathrm{MEA}}\right)$. In this case, the modulation index of the inverter is determined from the DC bus voltage reference (U $\mathrm{U}_{\mathrm{DCREF}}$ ), the measured DC bus voltage $\left(\mathrm{U}_{\mathrm{DC}}\right)$, the reactive power input $\left(\mathrm{Q}_{\mathrm{REF}}\right)$ and the measured reactive power (Q). This PQ control algorithm allows to control the generation of active and reactive power. A detailed explanation can be found in [10]-[11].

In stand-alone mode, the microturbine controls must be able to control the voltage and frequency of the grid. These control algorithms are used for the isolated operation of a single microturbine or, in the case of being used as the master, in a master-slave configuration, for multi generation microgrids operating islanded from the main grid. In this case, the microturbine speed control actuates to maintain the DC bus voltage to its reference value. The inverter control algorithms follow the grid voltage setting $\left(\mathrm{U}_{\mathrm{D}}, \mathrm{U}_{\mathrm{Q}}\right)$ and the frequency reference set by an oscillator. This way, it is possible to keep voltage and frequency in their nominal values. These voltage-frequency control algorithms are described in [12]-[13].

\section{New centralized control algorithm in islanded mode for multiple generation systems}

When several microturbines are operating in an isolated microgrid, a high-level controller must supervise the voltage and frequency of the microgrid. This controller modifies the power references of the microturbines primary controllers. Individual microturbines will operate according to a PQ control mode. Therefore, the possibility of setting the active power value to be generated by each microturbine is maintained, which, in most of the cases, it will be proportional to the thermal energy needs at the microturbine location.

The high-level controller proposed is based on a centralized controller that distributes the required active and reactive power among all the microturbines to balance the microgrid.

Figure 2 shows P-f (active power-frequency) and Q-V (reactive power-voltage) control loops of the centralized controller. In case of frequency unbalance, an active power variation is calculated for each microturbine. Conventional control algorithms share the needed power among the microturbines according to equations (1) and (2).

$d p_{k}=s f p_{k} \cdot\left[K P_{p}\left(f-f_{\text {ref }}\right)+K P_{i} \int\left(f-f_{\text {ref }}\right)\right]$
$d q_{k}=s f q_{k}\left[K Q_{p}\left(V-V_{\text {ref }}\right)+K Q_{i} \int\left(V-V_{\text {ref }}\right)\right]$

Where:

- $d p_{k}$ and $d p_{q}$ : active and reactive power shared by 
microturbine $\mathrm{k}$

- $\quad s f p_{k}$ and $s f q_{q}$ : sharing factor for active and reactive power of microturbine $\mathrm{k}$

- $K P_{p}, K P_{i}, K Q_{p}$ and $K Q_{i}$ : proportional and integral gains for the active and reactive control loop, respectively

This calculation would result in a share by each microturbine of the required additional active or reactive power in proportion to its sharing factor.

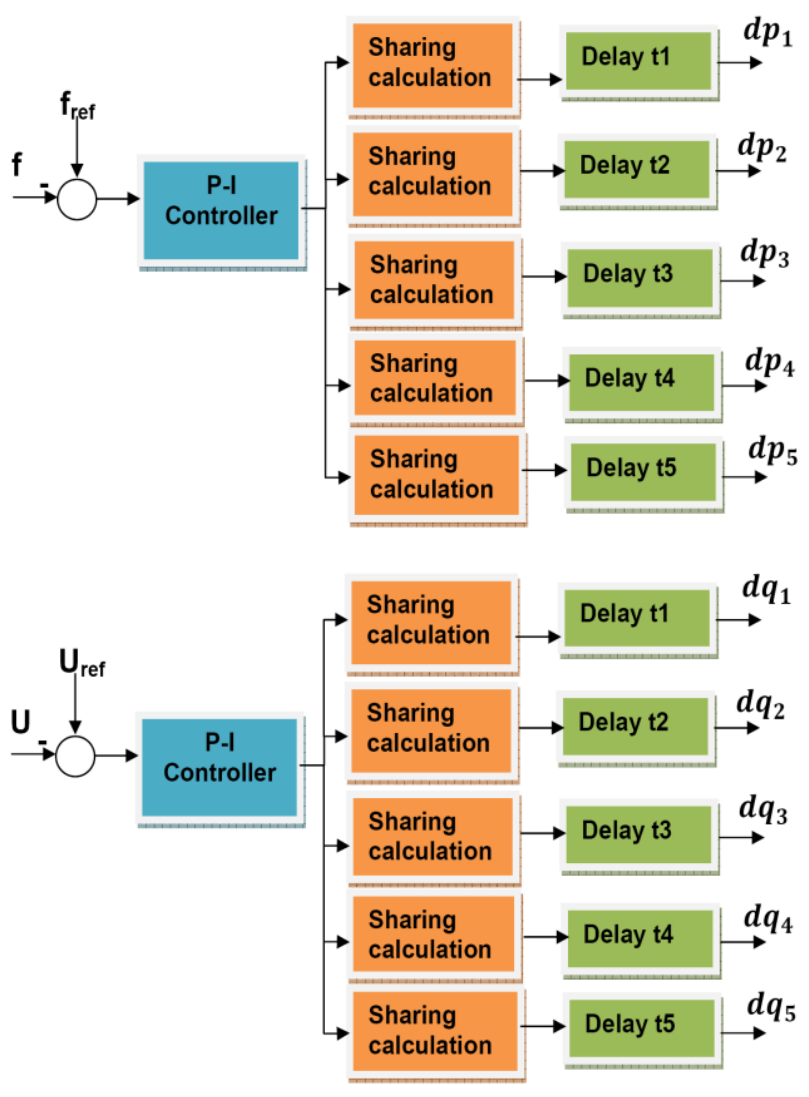

Fig 2. Centralized P-f and Q-V control loops

The algorithm presented in this paper modifies the sharing principle for the active power variation to improve the global efficiency of the microgrid. When the power variation to be shared is positive, equation (3) is applied while, when negative, equation (4) is applied.

$\Delta P_{k}=\left(1-\frac{\left|\Delta \varepsilon_{k}\right|}{\sum_{i=1}^{n}\left|\Delta \varepsilon_{i}\right|}\right) d p_{k}$

$\Delta P_{k}=\frac{\left|\Delta \varepsilon_{k}\right|}{\sum_{i=1}^{n}\left|\Delta \varepsilon_{i}\right|} d p_{k}$

Where:

- $\Delta P_{k}$ : Active power shared by microturbine $\mathrm{k}$

- $\Delta \varepsilon_{k}$ : Global efficiency difference of microturbine $\mathrm{k}$ caused by the active power change

- $\quad \sum_{i=1}^{n}\left|\Delta \varepsilon_{i}\right|$ : Summation of the global efficiency change of every microturbine.

The global efficiency of each microturbine is calculated using approximated functions of the efficiency curves. The global efficiency values at the actual operating point and the new operating point are determined to calculate the efficiency difference caused by the active power change.
The proposed algorithm also considers the operating limits of each microturbine. When one of the microturbines reaches the maximum or the minimum power, the power to be shared by this microturbine is calculated as the difference between the current operating point and the maximum or minimum. The rest of the microturbines must assume the power that this microturbine has not been able to generate.

The result of the proposed centralized algorithm, $\Delta P_{k}$, is the calculated additional power provided by microturbine $\mathrm{k}$. This value is applied to the primary P-f control, as shown in Figure 3.

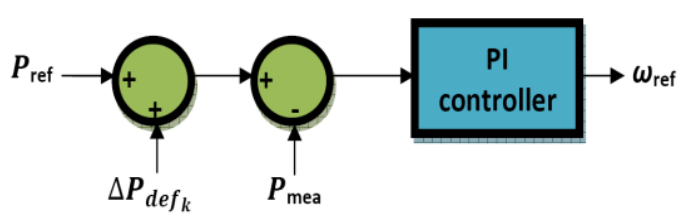

Fig 3. P-f primary control scheme of microturbines

When centralized controllers are used, special attention must be paid to the effect of communication delays. These delays may affect the performance and stability of the microgrid controls [14-16]. For this reason, delay blocks have been included in the model to check the effect on the stability of the microgrid. These blocks have been also included in the operation mode signal applied to microturbine and inverter controls.

\section{New control strategy for transition between operation modes}

The microturbine generation system must be able to make the transition between grid connected and islanded operation, in a seamless and automatic way. For each operation mode, different control loops are used.

A new control strategy is proposed based on modifying the output error signals of the controllers and the input signals to them. The aim of this control strategy is, on the one hand, to cancel the error signal of the controllers which should not be active, so that there is no progressive increase of such errors. On the other hand, the signals that must feed the speed control and the inverter controls are different for each mode of operation. This way, the microturbine operated according to the existing mode of operation, overriding the controllers that should not operate for the active operating mode.

Similarly, for the inverter control, the modulation index is determined by different control loops, depending on the operation mode. Thus, in the grid connected mode, this calculation is performed by the PQ control algorithm and so, the Vf control loop must remain inactive. The proposed control strategy actuates maintaining these values at the last calculated value when the control loop was active, avoiding inconsistent values due to increasing errors. This control strategy allows the transition of the microturbine between operation modes without losing the entire microgrid. 
For the centralized controller, when the system is operating in grid connected mode, the output signals and the errors of the control loops must be cancelled, returning to its operating values in islanded operation mode. Table 1 shows the conditions that apply for each operating mode of the generating system. Two possibilities have been considered, grid connected and islanded with centralized control algorithm. The operating mode is set by the status of the switch at the Point of Common Coupling (PCC) of the microgrid.

Table I. Conditions applied to the generation system for each operation mode

\begin{tabular}{|c|c|c|}
\hline & $\begin{array}{l}\text { Grid } \\
\text { Connected }\end{array}$ & $\begin{array}{l}\text { Islanded } \\
\text { Centralized }\end{array}$ \\
\hline Microturbine & $\Delta P_{d e f_{k}}=0$ & - \\
\hline Inverter & $\begin{array}{l}\mathbf{U}_{\text {dref }}-\mathbf{U}_{\mathrm{d}}=\mathbf{0} \\
\mathbf{U}_{\mathrm{qre}}-\mathbf{U}_{\mathrm{q}}=\mathbf{0} \\
\Delta \boldsymbol{Q}_{\text {def }_{k}}=\mathbf{0} \\
\mathbf{P m}_{\mathrm{r}}=\mathbf{P m}_{\mathrm{rpq}} \\
\mathbf{P m}_{\mathrm{i}}=\mathbf{P m}_{\mathrm{ipq}}\end{array}$ & $\begin{array}{l}\mathbf{U}_{\text {dref }}-\mathbf{U}_{\mathrm{d}}=\mathbf{0} \\
\mathbf{U}_{\mathrm{qref}}-\mathbf{U}_{\mathrm{q}}=\mathbf{0} \\
\mathbf{P m}_{\mathrm{r}}=\mathbf{P m}_{\mathrm{rpq}} \\
\mathbf{P m}_{\mathrm{i}}=\mathbf{P m}_{\mathrm{ipq}}\end{array}$ \\
\hline $\begin{array}{l}\text { Centralized } \\
\text { Controller }\end{array}$ & $\begin{array}{l}\mathbf{f}_{\text {ref }}-\mathbf{f}=\mathbf{0} \\
V_{\text {ref }}-V=0\end{array}$ & - \\
\hline
\end{tabular}

\section{Validation and simulation results}

In order to test the validity of the proposed algorithms, a real low voltage network, including four $30 \mathrm{~kW}$ microturbines and one $60 \mathrm{~kW}$ microturbine (microturbine 1 ), has been modelled in PowerFactory simulation software. The microturbines have been modelled as indicated in Section 2, using operating data from a Capstone C30 microturbine [17]-[18], and with control algorithms of Sections 3 and 4.

To test the operation of the proposed centralized controller, a simulation analysis has been performed in islanding mode. Table II shows the initial values and Table III the events applied.

Initially, active power references have been changed for microturbines 2 and 3 , and later, the reactive power references of microturbines 2, 3 and 4 . Figure 4 shows the results obtained for active power generation, speed, reactive power generation and DC bus voltage of microturbine 1. Figure 5 shows voltage and frequency values at the PCC and Figure 6 the results for active and reactive power generation of microturbine 2 .

Table II. Initial values

\begin{tabular}{|c|c|c|}
\hline Generation System & P (p.u.) & Q (p.u.) \\
\hline Microturbine 1 & 0.46666 & 0.33333 \\
\hline Microturbine 2 & 0.83333 & 0.33333 \\
\hline Microturbine 3 & 0.83333 & 0.33333 \\
\hline Microturbine 4 & 0.83333 & 0.33333 \\
\hline Microturbine 5 & 0.83333 & 0 \\
\hline
\end{tabular}

Table III. Events

\begin{tabular}{|c|c|c|}
\hline Generation System & $\begin{array}{c}\text { Simulation } \\
\text { Time }\end{array}$ & Event \\
\hline Microturbines 2 and 3 & $\mathrm{t}=10 \mathrm{~s}$ & $\mathrm{P}_{\text {ref }}=0.3333$ p.u. \\
\hline Microturbines 2 and 3 & $\mathrm{t}=40 \mathrm{~s}$ & $\mathrm{P}_{\text {ref }}=0.8333$ p.u. \\
\hline Microturbines 2,3 and 4 & $\mathrm{t}=70 \mathrm{~s}$ & $\mathrm{Q}_{\text {ref }}=0$ p.u. \\
\hline Microturbines 2,3 and 4 & $\mathrm{t}=100 \mathrm{~s}$ & $\mathrm{Q}_{\text {ref }}=0.3333$ p.u. \\
\hline
\end{tabular}

As can be seen in the figures, the power generated does not perfectly follow the reference power, due to the voltage and frequency control performed by the centralized control algorithm and the power sharing. This way, each microturbine can establish its operating point, being able to take advantage of the thermal energy.

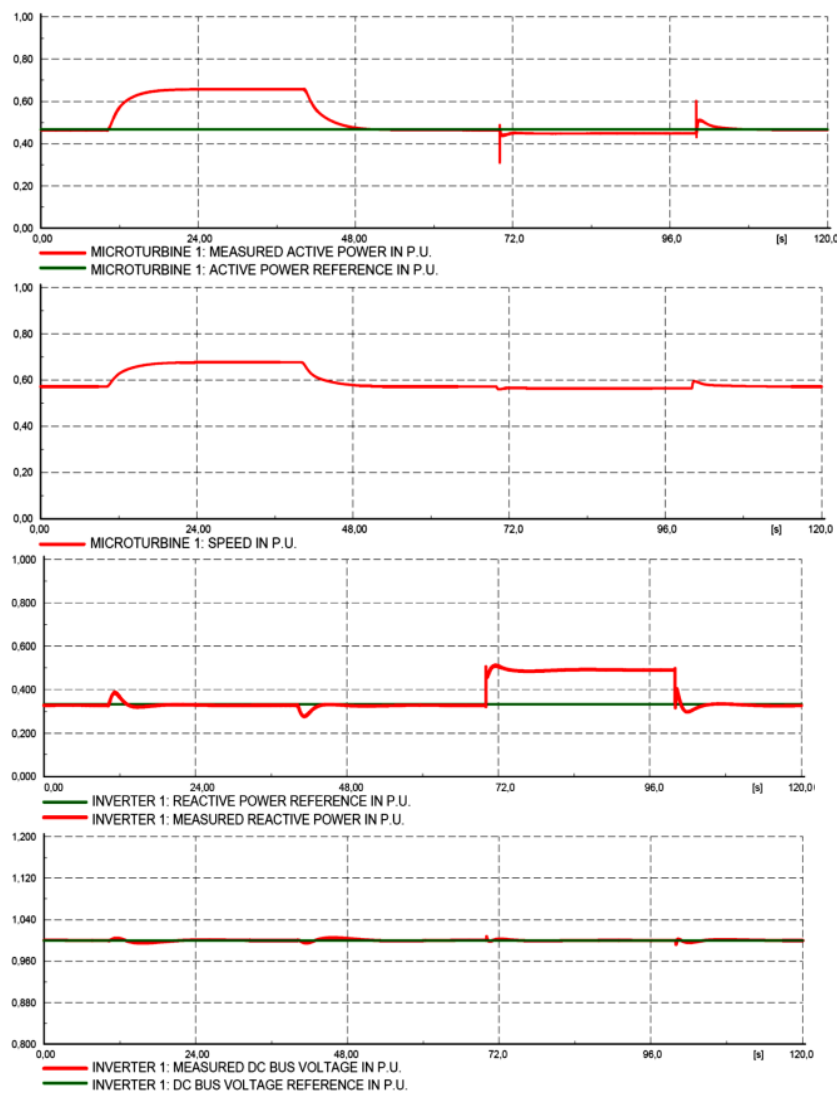

Fig 4. Active power generation, speed, reactive power generation and DC bus voltage of microturbine 1

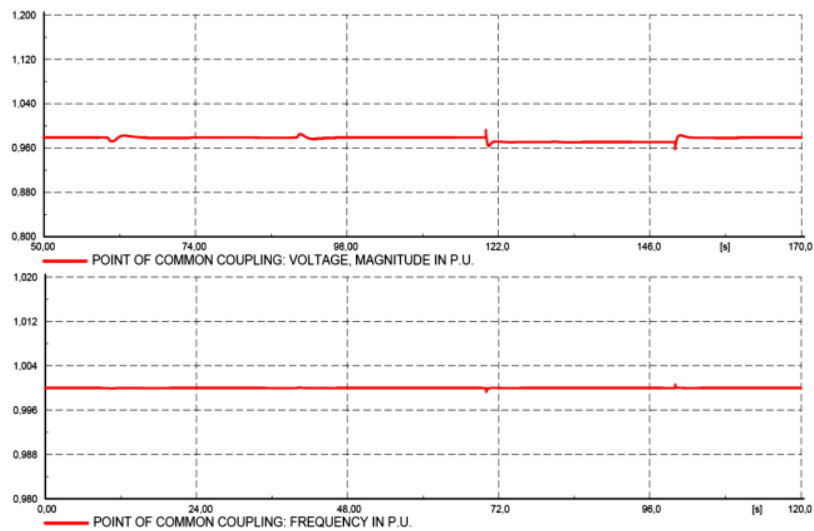

Fig 5. Voltage and frequency values at the PCC 


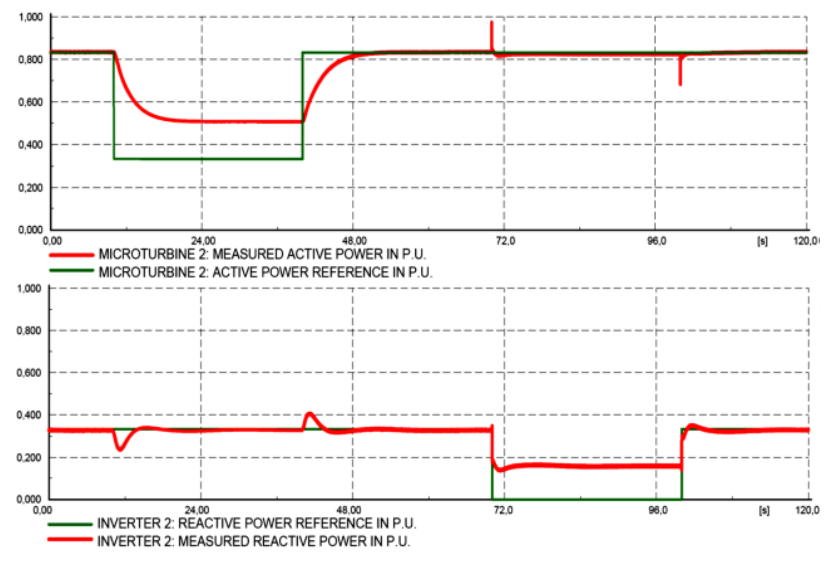

Fig 6. Active and reactive power generation of microturbine 2

Additionally, as it is shown in Figure 5, the transients produced in the voltage due to these changes are small in magnitude and occur with both active and reactive power changes. The same situation happens with the transients produced in the frequency of the microgrid.

To analyse the performance of the control strategy proposed for the transition between operation modes, several simulations have been carried out. As example, a case is presented in which the transition from the gridconnected to the islanding mode occurs at the instant of maximum export of active power to the utility grid. The islanding event occurs at $\mathrm{t}=10 \mathrm{~s}$ and the connection to the utility grid at $\mathrm{t}=30 \mathrm{~s}$. Figure 7 shows active power generation, speed, reactive power generation and DC bus voltage in microturbine 1 . Figure 8 shows voltage and frequency values at the PCC.

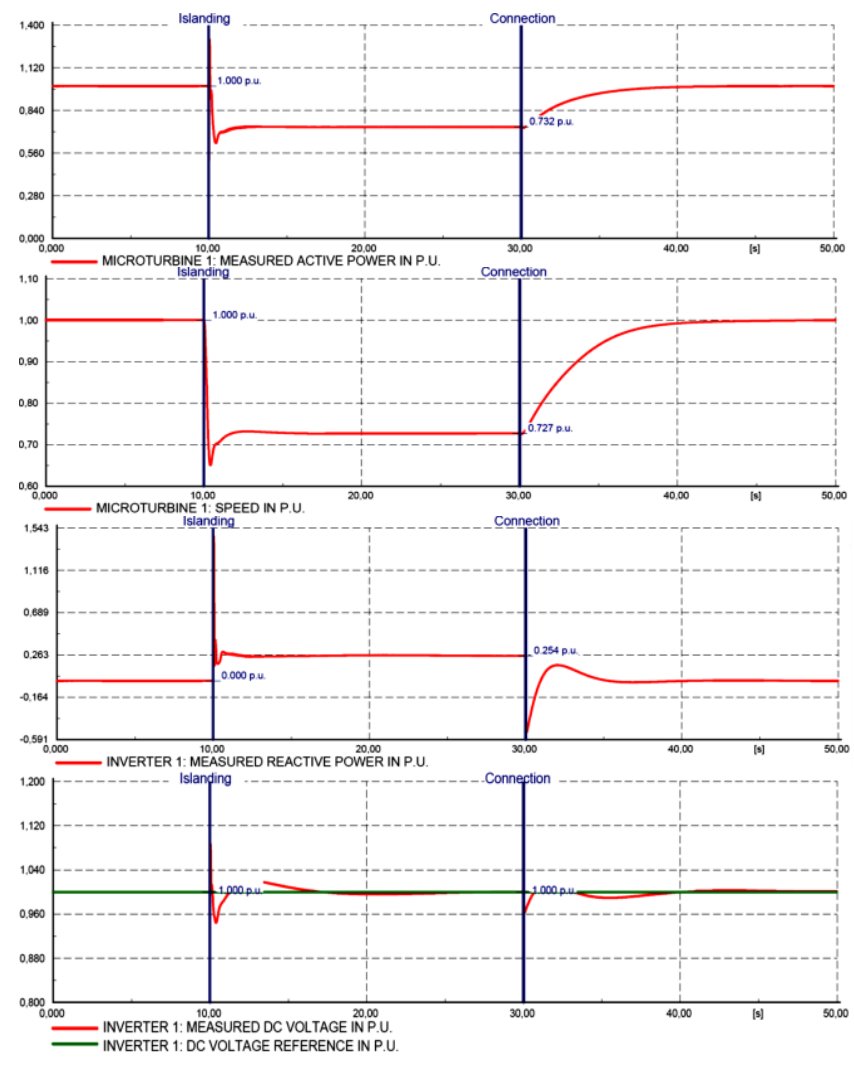

Fig 7. active power generation, speed, reactive power generation and DC bus voltage of microturbine 1 for the transition of the operation mode

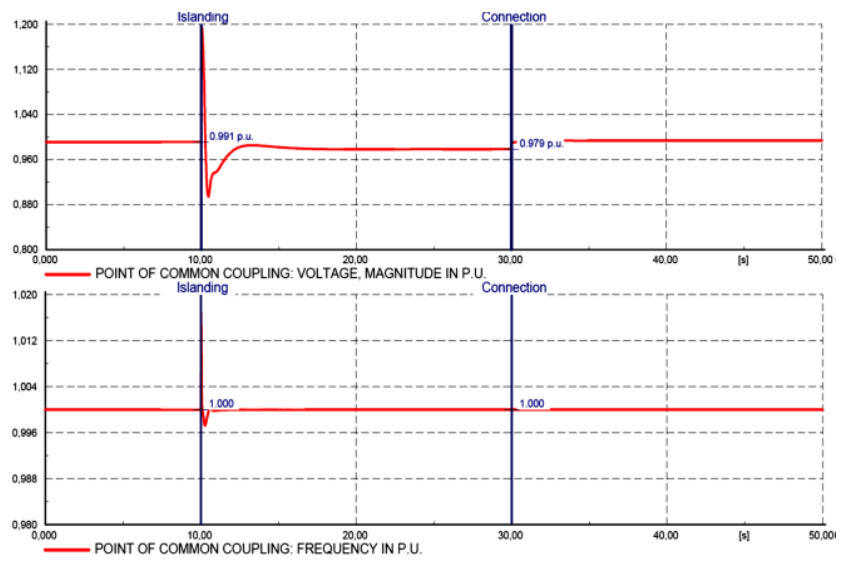

Fig 8. Voltage and frequency values at the PCC for the transition of operation mode

As can be seen in Figures 7 and 8, the system remains stable after the change of operation mode and becomes controlled by the centralized control algorithm. After reconnection to the utility network, the centralized control algorithm is disconnected per the conditions of Table I. The system returns to the operation of the PQ control algorithm, following the established references for each microturbine.

To verify the effect of the communications delay, the same simulation case has been repeated, with a communications delay of $100 \mathrm{~ms}$. The voltage and frequency at the PCC for this case are shown in Figure 9. The transients are larger but the microgrid remains stable.

Finally, the maximum delay for which the system remains stable, when the microgrid is exporting the maximum active power to the grid has also been checked. Loss of the microgrid occurs when the communications delay is greater than $130 \mathrm{~ms}$.

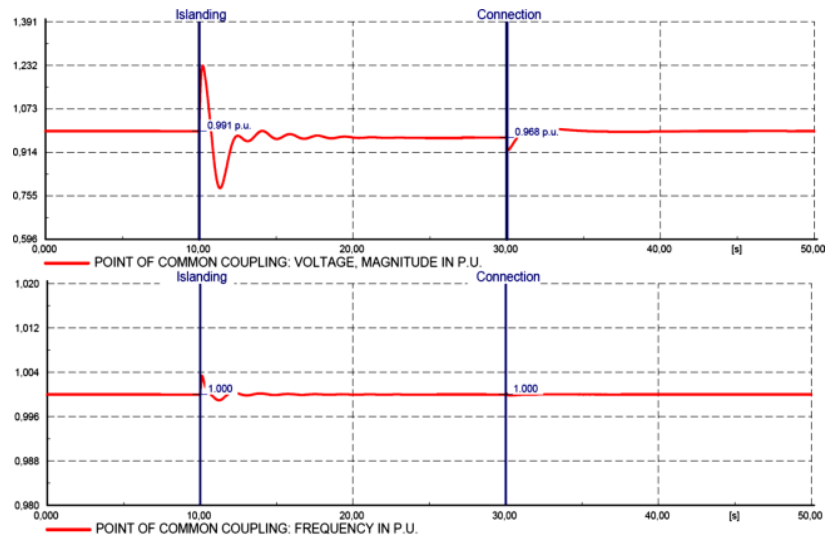

Fig 9. Voltage and frequency values at the point of common coupling for the transition of operation mode and a communications delay of $0.1 \mathrm{~s}$

\section{Conclusions}

This paper has presented a new control algorithm for islanding mode operation, applied to a microgrid based on microturbines. The proposed algorithm takes into account the thermal energy needs in the different locations of the microturbines and performs voltage and 
frequency control of the isolated grid, so that the overall efficiency in the system is improved.

Besides, a new control strategy for transition of operation mode has been presented. This strategy works on the controllers to cancel the error signals depending on the operation mode, and provides the appropriate input signals to the governor and the inverter controllers.

A test system implemented in PowerFactory software has been used to validate the proposed algorithms. The results show that the new centralized algorithm responds correctly to the changes produced in the microgrid, sharing the power to be generated when there are changes, both in loads and microturbines.

The disconnection and connection from the utility grid occurs without the loss of the system, through the use of the control strategy presented. The effect produced by the communications delay, for the modelled system, has been verified, establishing the maximum delay for which the system keeps the stability in the transition of the operation mode.

\section{Acknowledgement}

The work presented in this paper has been supported by the Basque Government research grant: group GISEL (Ref IT1083-16).

\section{References}

[1] ARAFAT, Md Nayeem, et al. Transition control strategy between standalone and grid-connected operations of voltage-source inverters. IEEE Transactions on Industry Applications, 2012, vol. 48, no 5, p. 1516-1525.

[2] Jin, Cheng, et al. A seamless transfer strategy of islanded and grid-connected mode switching for microgrid based on droop control. Energy Conversion Congress and Exposition (ECCE), 2012 IEEE. IEEE, 2012. p. 969-973.

[3] RANJBAR, Mahmoud, et al. Seamless transfer of threephase grid-interactive microturbine inverter between gridconnected and stand-alone modes. Electrical Engineering (ICEE), 2011 19th Iranian Conference on. IEEE, 2011. p. $1-6$

[4] LOPES, JA Peças; MOREIRA, C. L.; MADUREIRA, A. G. Defining control strategies for microgrids islanded operation. IEEE Transactions on Power Systems, 2006, vol. 21, no 2, p. 916-924.

[5] ENGLER, Alfred; SOULTANIS, Nikos. Droop control in LV-grids. 2005 International Conference on Future Power Systems. IEEE, 2005. p. 6 pp.-6.

[6] LASSETER, Robert. Dynamic models for micro-turbines and fuel cells. Power Engineering Society Summer Meeting, 2001. IEEE, 2001. p. 761-766.
[7] ROWEN, William I. Simplified mathematical representations of single shaft gas turbines in mechanical drive service. ASME 1992 International Gas Turbine and Aeroengine Congress and Exposition. American Society of Mechanical Engineers, 1992. p. V005T15A001V005T15A001.

[8] CAO, Xu; YE, Jian-hua. The Predictive Control of Microturbine Generation System. 2012 Asia-Pacific Power and Energy Engineering Conference. IEEE, 2012. p. 1-4.

[9] SAHA, A. K., et al. Modelling and simulation of microturbine in islanded and grid-connected mode as distributed energy resource. Power and Energy Society General Meeting-Conversion and Delivery of Electrical Energy in the 21st Century, 2008 IEEE. IEEE, 2008. p. 17.

[10] NAYAK, Sanjeev K.; GAONKAR, D. N. Modeling and performance analysis of microturbine generation system in grid connected/islanding mode. Power Electronics, Drives and Energy Systems (PEDES), 2012 IEEE International Conference on. IEEE, 2012. p. 1-6.

[11] BLAABJERG, Frede, et al. Overview of control and grid synchronization for distributed power generation systems. IEEE Transactions on Industrial Electronics, 2006, vol. 53, no 5, p. 1398-1409.

[12] MOHAMED, Azah; NIZAM, Muhammad; SALAM, A. A. Performance evaluation of fuel cell and microturbine as distributed generators in a microgrid. European Journal of Scientific Research, 2009, vol. 30, no 4, p. 554-570

[13] LI, Gang, et al. Modeling and simulation of a microturbine generation system based on PSCAD/EMTDC. Critical Infrastructure (CRIS), 2010 5th International Conference on. IEEE, 2010. p. 1-6

[14] LIANG, Hao, et al. Stability enhancement of decentralized inverter control through wireless communications in microgrids. IEEE Transactions on Smart Grid, 2013, vol. 4, no 1, p. 321-331.

[15] QIU, Robert Caiming, et al. Cognitive radio network for the smart grid: experimental system architecture, control algorithms, security, and microgrid testbed. IEEE Transactions on Smart Grid, 2011, vol. 2, no 4, p. 724740.

[16] LIU, Shichao; WANG, Xiaoyu; LIU, Peter Xiaoping. Impact of communication delays on secondary frequency control in an islanded microgrid. IEEE Transactions on Industrial Electronics, 2015, vol. 62, no 4, p. 2021-2031.

[17] Moya, Marta, et. al. Performance analysis of a trigeneration system based on a micro gas turbine and an air-cooled, indirect fired, ammonia-water absorption chiller. Applied Energy, 2011, vol. 88, no 12, p. 44244440.

[18] Eguia, Pablo, et al. Modelling and Simulation of a Microturbine during Transient Events. International Conference on Renewable Energy and Power Quality 2010, p 1-6. 